\title{
ANÁLISIS RETÓRICO DE LA POESÍA
}

(MODESTAS PROPOSICIONES PARA UNA TEORÍA DE LO POÉTICO QUE QUISIERA DECLARARSE CIENCIA)

Para v. M.

A. V.

En las regiones de lengua francesa, es decir aquéllas culturalmente enfeudadas en París por lo menos en las disciplinas humanísticas, el estudio de las obras de arte literario se ha renovado durante la década de los años sesenta, como consecuencia del descubrimiento tardío - gracias a algunos inmigrados- de los trabajos de los formalistas rusos, por la traducción reverberante de dos estudios famosos de Roman Jakobson, y también como consecuencia del impulso de distintas ciencias humanas por la moda estructuralista. La publicación, en la seria revista L'Homme, del famoso análisis de Los gatos de Baudelaire, firmado por dos de los mayores sabios de la época, puede servir como punto de referencia. Poco después, en un dominio que se dividía entonces, por una parte, en una "crítica literaria" sin fundamento metodológico más que la intuición y el ingenio del comentarista y, por otra parte, en una "estilistica" practicada principalmente por los universitarios, cuyos criterios, sin embargo, estaban lejos de ser estables y definidos, gran parte de los trabajos de investigación se reagruparon, alrededor del año de 1970, en torno a la enseñanza de-la "poética". Este campo de investigación, cuya homogeneidad no es flagrante, incluye aquello que se ha definido -.explícitamente o nocomo una neorretórica. El Grupo $\mu$ de Lieja ha contribuido al replanteamiento de algunos conceptos heredados del vasto corpus de la retórica clásica, y en especial de lo que se llamará aquí, por razones de brevedad, las "figuras del 
lenguaje". ${ }^{1}$ Puede advertirse que las relaciones entre la "poética", en el sentido actual de la palabra y la neorretórica, en el sentido de una teoría generalizada de las figuras, no han sido entendidas siempre de la misma manera. ${ }^{2}$

Si se desciende del plano de la teoría al de la práctica institucional, cuyo modelo sería la revista parisina Poétique, puede comprobarse, ante todo, que la materia tratada en esa publicación en general se ha tomado de lo que ha sido congrado como "literatura" por la institución académica; en otras palabras, que la poesia, en el sentido cómún del término, está lejos de ser el objeto exclusivo de la "poética" moderna.

Además, la afirmación según la cual la teoría de la literatura incluye necesariamente una teoría de la figura no debe permitix que se pierda de vista el hecho de que los "ornamentos" retóricos se manifiestan en todo tipo de prácticas heterogéneas, que en general no se incluyen en lo que llamamos literario.

Es posible superar fácilmente esta supuesta aporía al tomar en considerción la distinción propuesta, ya varias veces, por Etienne Souriau entre arte implicado y arte explicitado. La figura, en el sentido más amplio del término, puede producirse más o menos conscientemente, y utilizarse con fines persuasivos o estéticos. Para tomar sólo un ejemplo, los mensajes publicitarios presentan casi constantemente una tasa clevada de "retoricidad", tanto en lo que se refiere a su aspecto lingüístico como al visual. Pero esto no debe confundir al esteticista: sabemos desde hace mucho que el arte ha vivido con frecuencia en condición de sirviente, es decir de esclavo, con los mismos riesgos de fracaso o de éxito intrínsecos que cuando ha querido ser o imaginarse libre para sí mismo.

¿Cómo puede un acercamiento retoricista contribuir a de-

1 En "Miroirs de la Rhétorique" in Poétique, 29, hemos explicado un poco el alcance de la obra Rhétorique gértérale, Paris, Larousse, 1970, de la que se encuentra un buen resumen en Helena Beristáin, Guia para la lectura comentada de textos literarios (Parte 1), México, 1977.

"Cf. Philippe Minguet, "Du rhétorique au poétique" in Vers une esthétique sans entraves. Melanges d'esthdique prósentés à Mikel Dufrenne (Col. 10/18), 1975. 
finir la naturaleza de lo poético como "categoría estética"? Utilizo esta expresión en el sentido convencional en que se emplea en la terminología de los esteticistas de lengua francesa. $^{3}$

No se trata aquí de juicios de apreciación, lo que nos hace evitar el término de "valor", utilizado a veces en este sentido, pero que puede contaminar el problema de las esencias con el de las preferencias. En breve, lo poético, lo trágico, lo cómico, lo fantástico, etc,, son efectos o ethos, que pueden identificarse sin ser apreciados. Esta posición que tomamos como nuestra, no es la de todos los filósofos del arte, y tratándose en particular de lo poético, podríamos citar fácilmente las opiniones que ligan la existencia misma del ethos a su calidad, en el sentido axiológico. En nuestra opi-

3 Ver el artículo bien documentado de Anne Souriau, "La notion de cathégorie esthétique". in La Revue Esthétique (Paris, 1966). La autora no distingue tan claramente como lo desearlamos la noción de ethos y la de valor estético. De todas maneras, pone en evidencia esta distinción y sugiere al lector que elabore un cuadro con doble entraca:

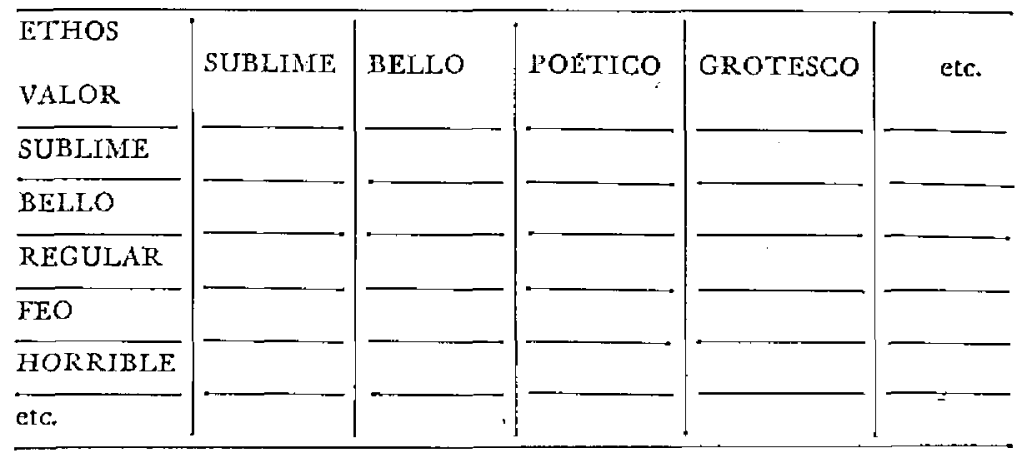

En una matriz de este tipo, las columnas verticales representan los grados de éxito en reiación con los ethos producidos, dispuestos horizontalmente. Es evidente que no tenemos los medios para realmente estructurar este cuadro, cuyo valor es sólo sugerente. Por una parte, la cucstión de saber si la lista de ethos es cerrada está lejos de resolverse; por otra parte, la escala de valoración no es lítil sino para recordar el carácter comparativo y no superlativo del valor estético. Se ha puesto en el primer espacio del cuadro el clásico término de "sublime" para recordar la tradición ambigua que hace de este término tanto un ethos como un grado supremo de valor. 
nión, el juicio de valor es de un orden distinto al de la identificación de un efecto, aunque puede admitirse que el grado de pureza del ethos investigado pueda fundar el juicio de apreciación.

Antes de presentar nuestra definición de lo poético, sin embargo, conviene agregar otra consideración relativa a la posición clásica respecto del problema del ethos. Las clasificaciones determinadas por muchos esteticistas a partir del siglo xvirl, ya sea por vías especulativas o por la observación empírica, con frecuencia dejan una impresión de fragilidad y de arbitrariedad, tanto cuando se limitan a ciertas categorias fundamentales (tres o seis) como cuando se esfuerzan por refinar las distinciones (veinticuatro o sesenta y seis, etc.). Por sugestiva que sea la "rosa de los vientos" propuesta por Etienne Souriau en su obra de 1933, Art et vérité, no implica una adhesión sin reservas. Esta clasificación pone en evidencia seis ethos fundamentales o clásicos (bello, sublime, trágico, grotesco, cómico, bonito) e introduce como grados intermedios otras dieciocho categorias, de las cuales seis se consideran típicamente románticas (enfático, patético, dramático, irónico, fantástico, poético) .

En un sentido tradicional, la categoría estética debería ser una posibilidad abierta a todas las artes. En otras pala-. bras, el ethos es, en principio, independiente del medio. Es un lugar común extender lo poético no sólo a los textos novelescos, sino también a las obras pictóricas, a espectáculos naturales, etc. Aun así, lo trágico se encontrará no sólo en las piezas de Sófocles o de Racine, sino también en los Pensées de Pascal, en algún cuadro de Van Gogh o, una vez más, en la naturaleza o la realidad. Tales usos frecuentes implican ciertos equívocos que, sin duda, son el precio de las extrapolaciones, a veces fecundas, pero con frecuencia rápidas. Es por eso que, al intentar retomar el problema de lo poético, nos ha parecido más seguro partir de lo poemático, es decir, de textos considerados como poéticos tanto por la intuición como por la institución.

Al contrario de los temas más generalizados, la especificidad de lo poético resultaría, en nuestra opinión, de un modo particular de estructuración semántica. No es que 
minimicemos la importancia efectiva que desempeñan en la poesía las estructuras convencionales o particulares del plano de la expresión: verso, rima, ritmo, etc. No obstante, es un hecho que el fenómeno universal del "verso aplicado", aun si es derivado como lo afirma Jakobson, obliga a buscar otras determinantes además de las equivalencias fónicas. Tampoco pensamos que la tesis, hace no mucho favorecida en la semiótica poética, del isomorfismo en el plano de la expresión y el plano del contenido sea realmente específica; también en este caso el mismo procedimiento puede encontrarse en el proverbio, el refrán, el juego de palabras, etc.

La ventaja de nuestro punto de vista es que da cuenta de un hecho de observación usual. Aun cuando el poema escrito en una lengua que no es la nuestra se reduce a un tipo de música rudimentaria, el efecto poético resiste -al menos parcialmente - la prueba de la traducción, a pesar de lo que se ha dicho al respecto. Esquematizaremos, pues, aquí las consideraciones teóricas que se pueden encontrar ilustradas rápidamente en algunos análisis publicados a paitir de 1972 y desarrollados en Rhétorique de la poésie."

1. El poema se caracteriza, como todo discurso retórico, de los que constituye una clase particular en lo que a esto se refiere, por su tendencia a la poliisotopia. Esta noción, derivada de los estudios de Greimas, designa el hecho de que el texto retórico rompe con la ley de la isasemia o coherencia semántica que rige el discurso puramente informativo.

2. El poema tiende, además, a un efecto de totalidad fundado sobre la oposición más general del universo semántico

' Grupo $\mu$ (Centro de estudios poéticos de la Universidad de Lieja), Jacques Dubois, Francis Edeline, Jean-Warie Rinkenberg, Philippe Minguet, Bruselas, F.ditions Complexe (đifusión P.U.F.), 1977. Los gérmenes de esta obra se encuentran ya en el ensayo de F. Edeline, "Champ analogique et structure narrative d'un poème français", traducción al español en F. Edeline y otros, Andilisis estructural del texto poético, Buenos Aires, Rodolfo Alonso Editor, 1973. El esquema del modelo triádico (anthropos, logos, cosmos) está anexado al análisis de un poema de Paul Elluard publicado bajo el título de Rhétorique poétique en el número 10 de Ios Documents de travail et prepublications del Centro Internazionale di Semiotica e di Linguistica (Unircrsidad de Urbino), publicado posteriormente en The Romanic Review, 1972. 
inmanente. Texto autónomo, autosuficiente, el poema se presenta como "modelo reducido" del universo sobre el que se experimentan las operaciones del lenguaje "sin peligro". Simbolizaremos esta distinción primordial, cuya parte epistemológica no se discute aquí, con los términos

\section{Anthropos vs cosmos}

Según el caso, puede ser más funcional recurrir: a oposicionas análogas o derivadas (subjetivos/objetivos o naturaleza/ cultura o extraceptivo/intraceptivo, etc.) .

3. En tanto que objeto propiamente poético, el poema realiza una mediación entre las dos categorías polares. Esta mediación es purannente verbal, pero comprende tres modalidades que pueden acumularse, y sobre las que hablaremos más adelante. En otras palabras, entre el anthropos y el cosmos, el poeta establece una unidad mediante el logos. . Estos tres rasgos definidores del poema desde luego no están presentados en un orden que corresponda al curso real de la producción del texto, aunque algunas estrategias de lectura, programadas por el mensaje, puedan corresponder a esta secuencia: 1) descubrimiento de por lo menos dos isotopías, de las que 2) una representa el sentido humano (anthropos) y la otra el sentido mundano (cosmos); enseguida, y a veces in extremis, 3) el descubrimiento de una reducción posible de la oposición.

Tomemos como ejemplo el siguiente poema de Octavio Paz:

$$
\text { AQUI }
$$

Mis pasos en esta calle

Resuenan

Donde

En otra calle

Oigo mis pasos

Pasar en esta calle

Donde

Sólo es real la niebla 
A pesar de su concisión, este texto responde a los tres criterios arriba mencionados. Si bien deben tomarse en cuenta los paralelismos impuestos por la disposición tipográfica, casi caligramática; si bien importa prestar atención a las figuras (como la paronomasia pasos/pasar), a las repeticiones (calle, calle, calle; pasos, pasos; donde, donde, etc.), a las oposiciones (esta, otra); ante todo, parecería necesario, para distinguir un texto como éste de un anuncio publicitario como:

\section{"Avec Sabena vous y seriez déja"}

escuchar, junto con el poeta ("anthropos"), su diálogo ("Iogos") con la exterioridad ("Cosmos") ."

Recogida dentro de límites estrictos como éstos, la intención poética acusa su estatismo fundamental. Es bien sabido, además, que, sin llegar a la brevedad del one-word poem de un I. H. Finlay, la concepción de la poesía moderna en generai tiende hacia lo compendiado. Una forma como el soneto, que alguna vez pasaría como haiku ("un soneto sin defecto..."),-nos parece hoy relativamente "larga". En todo caso, es una dimensión que conviene explorar sistemáticamente en sus procedimientos poéticos, tales como se en-cuentran por ejemplo en la obra de Mallarmé. Muchas series sémicas yuxtapuestas o interrelacionadas pueden desprenderse por medio de una lectura adecuada. La mediación propiamente retórica - $\mathrm{y}$ que, por otra parte, produce, todo siendo igual, el efecto poético más fuerte- implica que las unidades que constituyen una isotopía del tipo "anthropos" puedan leerse también, en todo o en parte, como pertenecientes a una isotopía del tipo "cosmos". La presencia de una isotopía de tipo "logos" - lo que es frecuente en la poesía modema - refuerza el carácter verbal de la media-

- Queda claro que éste no es un análisis del poema de Octavio Paz, recogido en Salamandra. Un estudio un poco más detallado podria ser tan largo como el que se encuentra en Ia Rhétorique de la poésie sobre un poema de e. e. cummings, que consiste de $\leq$ palabras. Se puede señalar por lo menos un rasgo notabie: en el poema "Aqui" el primer semema contiene el sema stijeto y el último el sema abjeto. 
ción. Una poesía más tradicional se limita a relacionar explícitamente dos series sémicas mediante los copulativos tradicionales: "como", "es", etc. Entre esta mediación discursiva y la mediación retórica existe la misma diferencia que entre la comparación y la metáfora pura. Un tercer procedimiento mediador, que puede llamarse pretextual o referencial, consiste en mencionar en el texto términos considerados como procedimientos mediadores en los códigos miticos y simbólicos.

En resumen, el ethos poético resulta del descubrimiento o, más bien, de la construcción por parte del lector, a partir de una estructura textual adecuada, de una mediación que radicalice la función unificadora del lenguaje. Tal ethos sería, desde luego, euforizante, con la condición de que se prestara al juego; desde un punto de vista ético o ideológico, puede ser irritante el simulacro poético; esto le sucede a los mejores poeticistas e incluso a los poetas mismos.

Se intentará aquí ilustrar las tesis desarrolladas en Rhetórique de la poésie mediante el análisis esquemático de un poema de Marcel Thiry, tomado de una de sus recopilaciones de juventud. ${ }^{\circ}$ Este texto ha sido el objeto de estudio en varios trabajos de estudiantes de la Universidad de Lieja. Nos limitaremos, pues, a presentar un cuadro relativamente simplificado, resultado de muchas lecturas, $y$ a algunas indicaciones explicativas, aunque nos remitimos a la obra ya mencionada para lo que se refiere al desarrollo teórico. ${ }^{\top}$

B Toi qui palis au nom de Vancouver, 1921 ( título tomado para la publicación de las obras poéticas completas en Seghers). Sobre Marcel Thiry, poeta y cuentista, el ensayo más accesible es el de Roger Borlart, colección "Poètes d'aujourd'hui", I24. Nacido en 1900 en Charleroi, poeta y soldado a los diecisietc años, Thiry combatió en Galicia, atravesó Siberia, el Pacifico, América - sin pasar por Vancouver- y luego regresó a Juropa, a Lieja, donde permaneció como maderero, y después como secretario perpetuo de la Academia de Lengua y Literatura Francesa de Bélgica hasta su muerte.

7 Hubiera preferido presentar en México el dístico de Pau!-Jean Toulet:

Etranger, je sens bon. Cueille-moi sans remords.

Les violettes sont le sourire des morts.

porque conozco el analisis de memoria -dado que lo presenté en 1972 en Bucarest-; pero se puede encontrar en Rhétorique de la poésie. También me hubiera gustado analizar el poema de Paz, pero cso sera otra vez. 
1 La hollandaise avait à cause de ses îles

2 Un arôme mental de cannelle et de the;

3 Par des Indes sa voix nous paraissait hantée

4 Et versait a nos coeurs l'espoir des beaux exils.

5 Des femmes font penser à des barques; mais elle,

6 Avec sa marche égale et sa tranquillité,

7 Evoquait, sur un moite océan, la montée

\& Calme d'un paquebot profilé sur le ciel.

9 Les jeunes gens surtout sentaient à son passage

10 Comme un appel de ce maritime infini,

11 Et son corps les tentait comme une colonie;

I2 Cependant elle allait, sans fièvre et les yeux sages,

13 Parmi ce rêve et ces désirs d'elle insaisis.

14 Et traînait sans savoir son sillage d'Asie.*

\section{Polilsotopía DEL TEXTO}

Desde el primer verso se manifiesta una ruptura de isotopía por la relación "ilógica" entre el semema de la holandesa y e. de islas. Decir que el segundo es "alotópico" (no isotópico) en relación con el primero evidentemente no basta. Sin embargo, lo permitiría una aplicación simplista de las definiciones de isotopía presentadas en la Semántica estructural. Para establecer una isotopía no sólo se necesita la repetición de clasemas (redundancia de categorías semán-

La Hollandaise me pareció conveniente, en homenaje a los mexicanos que conocen el papel de los "flamencós" en la génesis del arte barroco hispanoamericano; $y^{\prime}$ en homenaje también a Teun A. vari Dijk y a Carla Stellweg.

* Traducción literal: La hoiandesa teria debico a sus istas/Un aroma mental de canela y téj/Por las Indias su voz nos parecía hechizada (acosada/Y vertía en nuestros corazones la esperanza de beilos exilios//Las mujeres hacen pensar en barcas; pero ella,/Con su caminar parejo y' su tranquilidad,/Evocaba, sobre un húmedo océano, el ascenso/Calmado de un paquebote perfilado sobre ei cielo.//La gente joven sobre todo sentia cuando pasaba/Como un llamado de este maritimo infinito, $/ Y$ su cuerpo los tentaba como una colonia;//Sin embargo ella andaba, sin fiebre y los ojos sabios (castos, serenos),/Por este sueño y estos deseos suyos inalcanzados, $/ Y$ arrastraba sin saberlo su estela de Asia. 
ticas), sino que además es importante que los semas exclusivos no estén en una posición sintáctica de determinación. En otras palabras, Greimass ha insistido sobre la condición positiva de la isotopía, pero ha descuidado la condición negativa. Entre el conjunto sémico que comprende los elementos "humano", "mujer", "de los Países Bajos", "singular", etc., y el conjunto constituido por "terrestre", "maritimo", "plural", etc., hay instrumentos sintácticos (verbo, locución preposicional) que provocan la alotopía.

Es la lectura retórica la que permite reducir la desviación, s por ejemplo, al interpretar la holandesa como antonomasia de su país. Recíprocamente, a partir de la percepción de la serie ERos, el semema islas, puede releerse metafóricamente.

Desde el principio, como se puede ver, la alotopía abre la posibilidad de una doble lectura, de la apertura del sentido en dos direcciones: la isotopía que llamaremos MUjerOBJETo y la isotopía ColonIA. Si se continúa esta manera de restablecer la coherencia del enunciado, se estará ante un caso de revaloración retrospectiva (se "corrige" la holandesa con Holanda, metasemema interpretaclo mediante la metonimia: Holanda es, por excelencia semiótica, -y como dijo Albert Camus - un país de marineros "orientados hacia Java, ia isla lejana"). Es evidentemente la lectura lineal, en su consecución, la que permite constituir las dos isotopias anunciadas ya en el primer verso. El cuadro presentado - resultado estático de un proceso que no explicamos aquí-permite ver de inmediato que las dos series se continúan hasta el final, ya sea según el sentido "normal" de las palabras (ortosememas) o bien según el sentido "figurado" (metasememas).

En el verso 2, una nueva alotopía (aroma mental, atribución de una cualidad espiritual a una substancia material) se reduce, a su vez, constituyendo el primer anillo de una nueva cadena de sentido, HOMBre-suJETo; el aroma está clasificado bajo la isotopía de colonia, como sinécdoque

- Sobre e: significado de las nociones usuales de "norma" y "desviación". ver sobre todo J. M. Klinkenberg, en especial su ponencia al VII Congreso Internacional de Estética (publicado en ACTES, Bucarest, 1976). 
de "Indias". Podría parecer superfluo aislar una isotopía NATEGACIÓN (numerada como 2 bis). El interés del desdoblamiento es poner en evidencia un campo semántico muy marcado, de todas maneras, ligado metonímicamente al campo de colonia, pero que desempeñará un papel especial en la combinación isotópica de la que hablaremos más adelante. Lo mismo puede decirse cle 4 (PASAJE), percibido intuitivamente en la primera lectura como importante. Queda aún la isotopía EROS, evidente, aunque no se apoye ortosemérmicamente más que en el primer hemistiquio del verso 11 (y su cuerpo los tentaba...). Por medio de la metáfora, en la mayoría de los casos, o de antífrasis (ojos castos), un gran número de palabras puede incluirse en este significado; y en última instancia todas. Por ejemplo, el aroma, la canela y el té, aunque no estén inscritos en la columna de EROS, podrían sentirse — si se puede decir así- como figuras del "olor de las mujeres". El procedimiento de revaloración retrospectiva, ya encontrado en el primer verso, se manifiesta aquí de una manera miry patente: la conquista colonial se convierte en deseo carnal (y al contrario).

A la izquierda del cuadro se encuentra una serie intitulada "isotopía subjuntiva". Esta expresión designa la secuencia que modaliza las isotopias objetivas o "indicativas", en el sentido de la terminología gramatical tradicional (el subjuntivo es el sentido de lo optativo, del deseo). Se trata de una isotopía secundaria con relación a las otras, ya que está constituida por apreciaciones del sujeto 'enunciador. Dicho sea de paso, el abuso de los términos eufóricos es uno de los rasgos característicos de la poesía de circunstancia. En el poema que nos ocupa, sucede que la instancia enunciadora (explicitada en el verso 4) es también la instancia que clesea (el HOMBRE-SUJETO).

Como se dijo más arriba, podría simplificarse el cuadro; podría también complicarse, por ejemplo, al aislar los sememas que constituyen más precisamente la COMUNICACIón (con voz, pensar, evocada, sin saber, etc.). Parece conformarse más a la lógica del poema integrar estos términos en la serie hombre-Sujeto (la troz de la mujer se da, sobre 
todo, como escuchada por el hombre; es una voz que no dice nada).

\section{Combinación ISOTÓPICA}

Para que un texto produzca el efecto de sentido "poético", no es suficiente, como acabamos de mencionar, establecer su poliisotopía. Los hilos de sentido que están interrelacionados no son cualesquiera sino que constituyen un sistema de oposiciones y de mediaciones. Las condiciones generales de lo poemático, ya mencionadas, se cumplen en esta lectura del poema de Marcel Thiry. La oposición anturopos v's. COSMOS es patente; sería suficiente la serie HOMBRE-SUJETO para constituir el primer miembro de la oposición fundamental (la mujer es ante todo una sinécdoque del cosmos; de hecho, la Colonia, la NAVEGACión y el ERos tienen aqui una posición un poco ambigua. Esta indecisión relativa contribuye a su carácter mediador en el texto).

El paso de una isotopía a otra está muy marcado sintácticamente por los copulativos usuales o sus equivalentes. Las metáforas más evidentes son de tipo comparativo o in praesentia (por ejemplo: las mujeres hacen pensar en barcas). Se puede hablar en este caso de mediación discursiva: el texto conecta en la superficie una serie con otra. En el último terceto, la interrelación es más cerrada. La mediación se hace más claramente retórica, la coordinación deja lugar a la substitución, todos los temas se concentran, incluso la subjetividad que desea; es interesante señalar que la primera palabra del poema es la holandesa y la última es Asia. En lo que se refiere a la mediación referencial o extratextual, ésta interviene expresamente en la serie de $\mathrm{PA}^{-}$ SAJE, metáfora de la mediación, y aún más por la secuencia de NAVEGACIÓN, cuyo papel de conector arquetípico se conoce en la poesia desde la Odisea hasta el Primero sueño.

Este tipo de análisis, apenas esbozado aquí, de ninguna manera pretende agotar el fenómeno poético. Puede completar, y sobre todo especificar, lo determinado por un estudio de apareamientos o de paralelismos, al estilo de Levin 


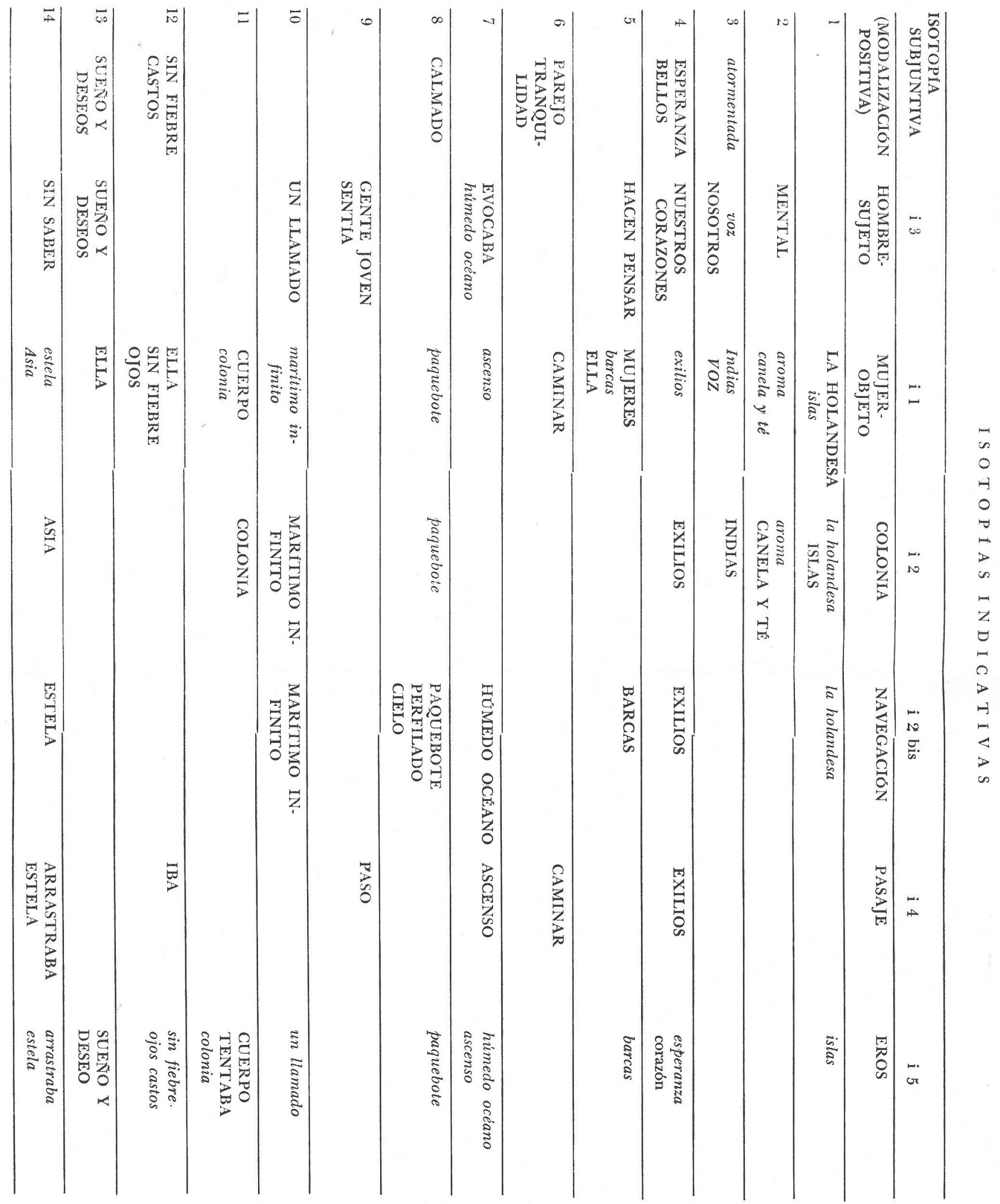


o de Jakobson. Una vez más, lo fundamental en nuestro objetivo metodológico ha sido marcar que el efecto de sentido poético se encuentra en primer lugar en el nivel de la forma del contenido.

A la manera de Roman Jakobson, en su admirable $P$. S. de Questions de poétique (París, Seuil), intentaremos disculpar lo que podría pasar como una obsesión por matrices, y logicista, con la invocación de un poeta universal. Numerosos son los artesanos del verbo que han afirmado que la poesía es esencialmente una mediación del lenguaje. Pero nadie, sin duda, lo ha hecho con mayor fuerza que Saint-John Perse en el discurso que pronunció hace dieciocho años bajo el simple título de "Poesía".

Desde 1910, el Premio Nobel de 1960 declaraba a Jacques Rivière:

Es cierto que jamás he tenido la idea de negarle al poema una misteriosa "concurrencia" musical (si no está preasignada); la utilización inconsciente del timbre verbal y' la distribución misma o la "composición" de toda una masa desde el momento en que vive. Pero no admitiría nunca que el poema pueda escapar, ni por un instante, a su propia ley: que es el tema "inteligible".

Philippe Mrnguet

(Grupo $\mu$ )

Universidad de Lieja 